\title{
A comparative study of the proventricular structure in twenty Chinese Tettigoniidae (Orthoptera) species
}

\author{
Yinliang Wang, Yuetian Su, Xue Zhang, Na Li \& Bingzhong Ren*
}

Wang, Y., Su, Y., Zhang, X., Li, N. \& Ren, B. 2012: A comparative study of the proventricular structure in twenty Chinese Tettigoniidae (Orthoptera) species. Entomol. Fennica 23: 140-148.

This study focuses on the proventriculus and the alimentary canal of twenty Tettigoniidae species among three subfamilies, Tettigoniinae, Phaneropterinae and Conocephalinae. Each part of the alimentary canal and the inner structure of proventriculus were examined under optic microscope and scanning electron microscopy. As a result, the length of each part of the alimentary canal and the inner structure of proventriculus were highly associated with feeding habits. Carnivorous species always had a short foregut and long cilia on the base of the sclerotized appendix in proventriculus, whereas herbivorous species always had a longer foregut and a highly sclerotized proventriculus. These results increase understanding of the alimentary canal in Tettigoniidae and will be useful in future studies of their feeding habits.

Y. Wang, X. Zhang \& B. Z. Ren, Jilin Key Laboratory of Animal Resource Conservation and Utilization, School of Life Sciences, Northeast Normal University, Renmin St. 5268, Changchun, China CO130024; *Corresponding author's email:bzren@163.com

Y. Su, Neurosurgery, the Second Norman Bethune Hospital of Jilin University, Yatai St. 991, Changchun China CO130024

N. Li, Traditional Chinese Institution, Shenyang Pharmaceutical University, Shenyang, 110016, China

Received 26 December 2011, accepted 19 March 2012

\section{Introduction}

The proventriculus is an organ situated between the foregut and midgut, its lumen lined by cuticle with teeth-like projections. These, together with associated well-developed muscles, aid food trituration process (Isely \& Alexander 1949).

The proventriculus is comprised of several sclerotized plates (Chapman 1998), whose structure has been adaptively associated with insect diet (Caetano 1988, Bland \& Rentz 1991). Moreover, many studies have shown that the morphol- ogy of proventriculus can provide useful taxonomic characters for Orthoptera (Judd 1948, Bland \& Rentz 1991, Fontanetti \& Zefa 2000, Fontanetti et al. 2002), Coleoptera (Judd 1947, Yahiro 1990), Isoptera (Lebrun 1985), Trichoptera (Gibbs 1967) and Hymenoptera (Roche \& Wheeler 1997, Serrão 2001, 2005, 2007). According to a new updated file of orthopteran species, there are more than 6,000 described Tettigonioidae species in the world (Eades et al. 2012), and there are more than 300 species of Tettigoniidae in China (Li \& Ren 2007), How- 
Table 1. List of twenty Chinese Tettigoniidae species examined with their collection locations and feeding habits.

\begin{tabular}{lll}
\hline Species & Location & Feeding habit \\
\hline Tettigoniinae & & \\
Gampsocleis sedakovii (Walker 1869) & Jilin, Tianbei & Omnivorous \\
G. ussuriensis (Adelung 1910) & Jilin, Songhua Lake & Omnivorous \\
G. gratiosa (Brunner von Wattenwyl 1888) & Inner Mongolia & Omnivorous \\
Uvarovites inflatus (Uvarov 1924) & Jilin, Zuojia & Herbivorous \\
Tettigonia caudata (Charpentier 1845) & Jilin, Tianbei & Omnivorous \\
T. cantans (Fuessly 1775) & Jilin, Songhua Lake & Omnivorous \\
T. ussuriana (Uvarov 1939) & Jilin, Tianbei & Omnivorous \\
Metrioptera ussuriana (Uvarov 1926) & Jilin, Baishan & Herbivorous \\
M. bonneti (Bolivar 1890) & Jilin, Songhua Lake & Herbivorous \\
M. bicolor (Philippi 1830) & Heilongiang, Dailing & Omnivorous \\
M. engelhardti (Uvarov 1926) & Jilin, Yaoling & Herbivorous \\
Atlanticus sinensis (Uvarov 1923) & Jilin, Yaoling & Carnivorous \\
Phaneropterinae & & \\
Phaneroptera falcata (Poda 1761) & Jilin, Tianbei & Omnivorous \\
Ph. nigroantennata (Brunner von Wattenwyl 1878) & Jilin, Tianbei & Omnivorous \\
Ducetia japonica (Thunberg 1815) & Jilin, Zuojia & Omnivorous \\
Elimaea fallax (Bey-Bienko 1951) & Jilin, Tianbei & Omnivorous \\
Conocephalinae & & Herbivorous \\
Conocephalus fuscus (Fabricius) & Inner Mongolia & Herbivorous \\
C. chinensis (Redtenbacher 1891) & Heilongjiang, Dailing & Herbivorous \\
Ruspolia nitidula (Scopoli) & Inner Mongolia & Herbivorous \\
R. jezoensis (Matsumura Shiraki 1908) & Jilin, Qingfeng & \\
\hline
\end{tabular}

ever, the inner structures of the proventriculus and the alimentary canal as a whole are still poorly known in Tettigonioidea.

In the present paper, the whole alimentary canal and the inner structures of the proventriculus in twelve species of Tettigoniinae, four species of Phaneropterinae and four species of Conocephalinae were investigated using stereomicroscope and scanning electron microscopy. The objective was to reveal the ultramorphological differences of the alimentary canal between representatives of these three largest subfamilies of Tettigoniidae.

\section{Material and methods}

\subsection{Studied material}

We used adult males as our study material. The species and collection localities are listed in Table 1. We classified the species by their morphology. The number of individuals studied for each species was 5-10.

\subsection{Scanning electron microscopy}

The male samples were immediately pre-treated with $8 \%$ formaldehyde solution. After 12-24 hours water flushing, the alimentary canal was carefully isolated from the specimen by ophthalmic scissors. The length of each part of the alimentary canal was measured under stereomicroscope (SMZ-168, Motic). Then the proventriculus was isolated from dissected guts and dissected with scissors through a single longitudinal cut. Subsequently, the samples were transferred to $15 \%$ cold $\mathrm{KOH}$ for 12 hours to facilitate the removal of muscle and connective tissue. The remaining flap of sclerotised tissue was washed, fixed $1-2 \mathrm{~h}$ in $2.5 \%$ glutaraldehyde, rinsed in 0.05 $\mathrm{M}$ phosphate buffer ( $\mathrm{pH} 7.2$ ), dehydrated in ascending alcohol series (50-100\%), and criticalpoint dried. After dried, the material was placed on aluminum supports attached with doublefaced tape and sputter coated with gold. The proventriculus was examined with scanning electron microscope (S-570, Hitachi) under an acceleration voltage of $20 \mathrm{kV}$. The lengths of each part of the alimentary canal and inner structure of 
proventriculus were measured under SEM and Digital calipers, and characters were observed under optic microscopy.

The following abbreviations are used for the studied structures

- $s a$ : sclerotized appendix

- $s p$ : sclerotized partition

- $m t$ : medium tooth

- $l t$ : lateral teeth

- $s l$ : sclerotized lobes

\section{Results}

\subsection{Gross morphology of the alimentary canal}

The lengths of the whole alimentary canal (Fig. 1), foregut, midgut, hindgut, proventriculus and gastric caeca were measured under stereomicroscope among three subfamilies Tettigoniinae, Phaneropterinae and Conocephalinae. The results are shown in Table 2. The foregut in Tettigoniinae was obviously longer than the midgut and hindgut, which accounts for about $40 \%$ of the whole alimentary canal. In the subfamily Phaneropterinae, the midgut accounted for over half of the whole alimentary canal, the hindgut for $20 \%$, and the foregut for $33 \%$. For the subfamily Conocephalinae, the proportions of different parts of the gut were very similar to the subfamily Tettigoniinae, i.e. a long foregut accounting for about $45 \%$, the midgut and hindgut accounting for $25 \%$ each.

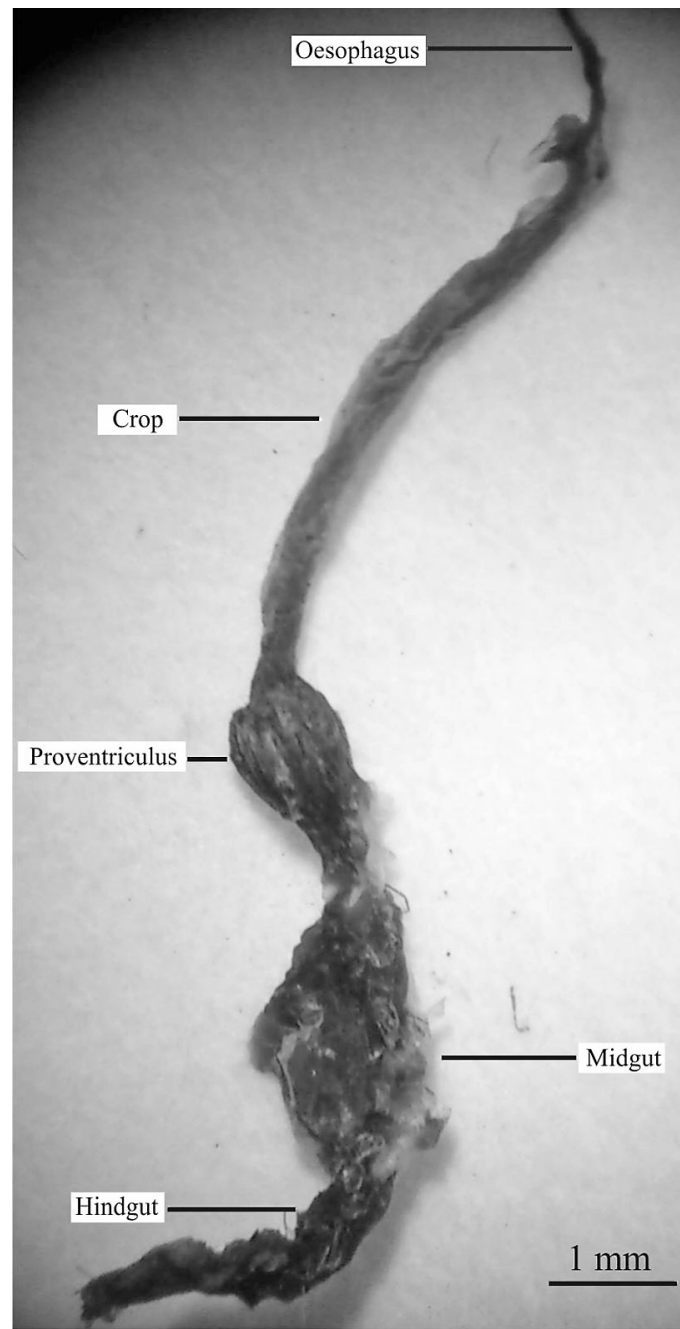

Fig. 1. Alimentary canal of Tettigoniidae species.

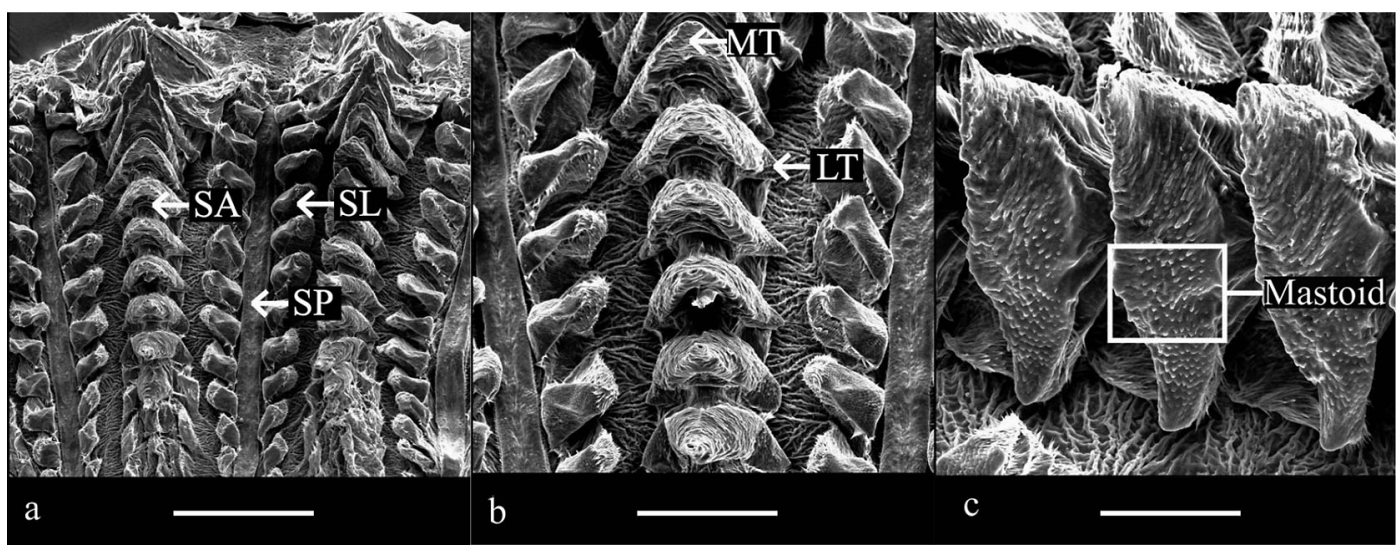

Fig. 2. Internal view of the proventriculus of Gampsocleis sedakovii (Walker 1869). - a. Distant view of longitudinal folds, scale $600 \mu \mathrm{m}$. - b. One longitudinal fold, scale $300 \mu \mathrm{m}$. - c. Lateral view of sclerotized appendices, scale $150 \mu \mathrm{m}$. 
Table 2. Length (mm) of alimentary canal of twenty Tettigoniidae species. Length of proventriculus was included in foregut and total length.

\begin{tabular}{llrrrrrr}
\hline Species & $\begin{array}{l}\text { Total } \\
\text { length }\end{array}$ & $\begin{array}{l}\text { Fore- } \\
\text { gut }\end{array}$ & $\begin{array}{l}\text { Mid- } \\
\text { gut }\end{array}$ & $\begin{array}{l}\text { Hind- } \\
\text { gut }\end{array}$ & $\begin{array}{l}\text { Proven- } \\
\text { triculus }\end{array}$ & $\begin{array}{l}\text { Gastric } \\
\text { caeca }\end{array}$ & $\begin{array}{l}\text { Body } \\
\text { length }\end{array}$ \\
\hline G. sedakovii & 55.60 & 22.10 & 16.80 & 16.70 & 4.20 & 5.96 & 40.10 \\
G. ussuriensis & 54.79 & 22.43 & 15.72 & 16.64 & 4.78 & 4.78 & 36.00 \\
G. gratiosa & 49.90 & 22.00 & 13.00 & 14.90 & 5.00 & 5.76 & 39.20 \\
U. inflatus & 51.88 & 20.42 & 15.20 & 16.26 & 3.12 & 4.22 & 18.20 \\
T. caudata & 47.90 & 24.80 & 10.60 & 12.50 & 3.68 & 5.46 & 32.20 \\
T. cantans & 45.50 & 24.10 & 10.40 & 11.00 & 3.90 & 5.78 & 31.00 \\
T. ussuriana & 46.30 & 24.50 & 10.60 & 11.20 & 3.16 & 4.10 & 32.25 \\
M. ussuriana & 37.26 & 14.34 & 10.20 & 12.72 & 2.82 & 3.14 & 18.75 \\
M. bonneti & 41.30 & 15.46 & 11.50 & 14.34 & 2.58 & 6.32 & 19.00 \\
M. bicolor & 35.68 & 13.70 & 9.58 & 12.40 & 1.94 & 3.00 & 21.75 \\
M. engelhardti & 34.20 & 13.00 & 9.00 & 12.20 & 2.20 & 3.00 & 17.50 \\
A. sinensis & 43.10 & 16.20 & 12.30 & 14.60 & 3.64 & 3.76 & 30.75 \\
P. nigroantennata & 44.44 & 16.30 & 22.56 & 5.58 & 1.24 & 2.40 & 15.00 \\
P. falcata & 49.52 & 17.66 & 25.10 & 6.76 & 2.10 & 4.16 & 14.50 \\
D. japonica & 38.90 & 20.50 & 12.20 & 6.20 & 2.40 & 3.12 & 18.50 \\
E. fallax & 47.06 & 20.94 & 15.96 & 10.16 & 2.52 & 3.52 & 17.50 \\
C. fuscus & 22.54 & 11.00 & 6.00 & 5.54 & 1.80 & 3.10 & 16.25 \\
C. chinensis & 21.68 & 9.28 & 7.10 & 5.30 & 1.64 & 1.94 & 16.75 \\
R. jezoensis & 34.94 & 14.84 & 10.22 & 9.88 & 2.20 & 4.72 & 20.75 \\
R. nitidula & 37.40 & 15.16 & 11.40 & 10.94 & 2.50 & 3.80 & 27.00 \\
\hline
\end{tabular}

Table 3. Characters of proventriculus of twenty Tettigoniidae species. Lengths and widths in $\mu \mathrm{m}$. Abbreviations: $s a$, sclerotized appendix; $s p$, sclerotized partition; $m t$, medium tooth.

\begin{tabular}{lccrrr}
\hline Species & No. of sa & Length of $m t$ & Width of $m t$ & Width of $s p$ & Length of sa \\
\hline G. sedakovii & 15 & 354.55 & 107.14 & 136.36 & $1,800.00$ \\
G. ussuriensis & 15 & 357.12 & 94.29 & 139.29 & $1,850.00$ \\
G. gratiosa & 15 & 340.91 & 136.36 & 147.27 & $2,359.09$ \\
U. inflatus & 12 & 261.70 & 69.11 & 99.82 & $1,190.18$ \\
T. caudata & 16 & 364.29 & 85.71 & 96.43 & $1,865.45$ \\
T. cantans & 16 & 415.18 & 120.54 & 93.75 & $2,181.82$ \\
T. ussuriana & 14 & 200.89 & 93.75 & 120.54 & $1,647.32$ \\
M. ussuriana & 12 & 352.36 & 96.73 & 72.18 & $1,174.55$ \\
M. bonneti & 12 & 349.09 & 123.64 & 87.27 & $1,258.18$ \\
M. bicolor & 12 & 374.91 & 101.22 & 82.91 & $1,084.36$ \\
M. engelhardti & 12 & 381.45 & 78.18 & 93.82 & $1,266.55$ \\
A. sinensis & 19 & 477.27 & 109.09 & 163.64 & $2,290.91$ \\
P. nigroantennata & 10 & 234.55 & 98.18 & 30.36 & $1,263.23$ \\
$P$. falcata & 10 & 226.36 & 89.45 & 44.28 & $1,266.83$ \\
D. japonica & 13 & 211.82 & 78.55 & 34.36 & 929.64 \\
E. fallax & 15 & 220.18 & 96.73 & 46.91 & $1,077.82$ \\
C. fuscus & 10 & 180.60 & 64.00 & 54.60 & 313.20 \\
C. chinensis & 10 & 163.64 & 54.55 & 54.66 & 224.14 \\
R. jezoensis & 13 & 347.09 & 103.64 & 96.73 & $1,043.27$ \\
R. nitidula & 13 & 354.55 & 109.09 & 90.91 & $1,327.27$ \\
\hline
\end{tabular}




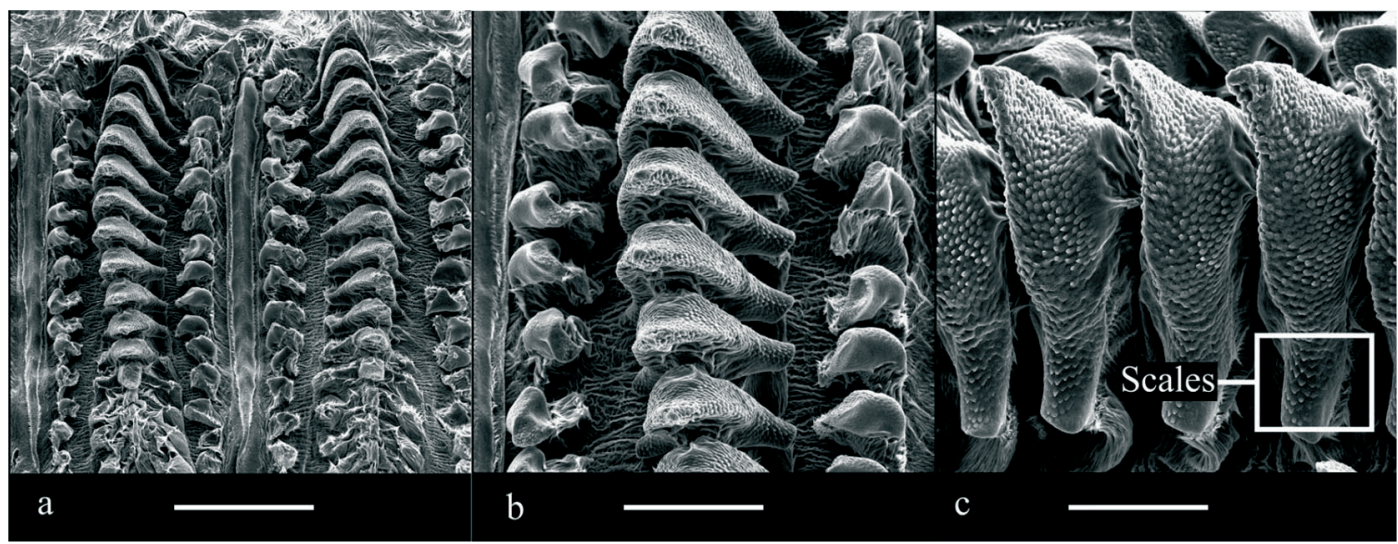

Fig. 3. Internal view of the proventriculus of Tettigonia caudata (Charpentier 1845). - a. Distant view of longitudinal folds, scale $600 \mu \mathrm{m}$. - b. One longitudinal fold, scale $250 \mu \mathrm{m}$. - c. Lateral view of sclerotized appendices, scale $150 \mu \mathrm{m}$.

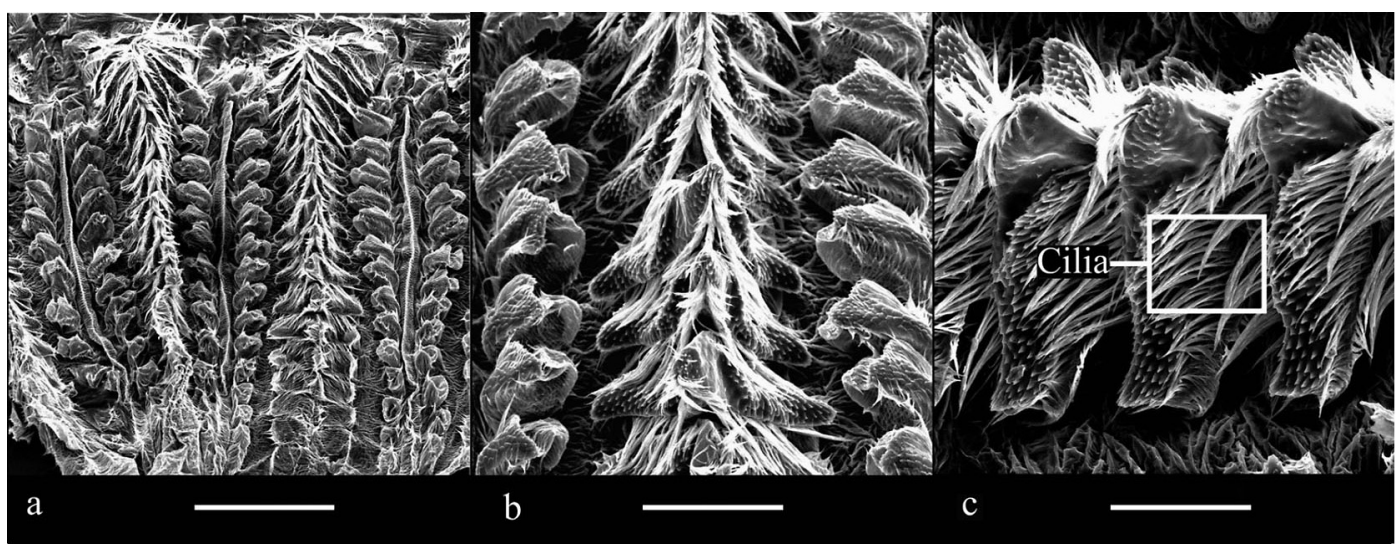

Fig. 4. Internal view of the proventriculus of Phanerotera nigroantennata (Brunner von Wattenwyl 1878). - a. Distant view of longitudinal folds, scale $430 \mu \mathrm{m} .-\mathrm{b}$. One longitudinal fold, scale $150 \mu \mathrm{m} .-\mathrm{c}$. Lateral view of sclerotized appendices, scale $100 \mu \mathrm{m}$.

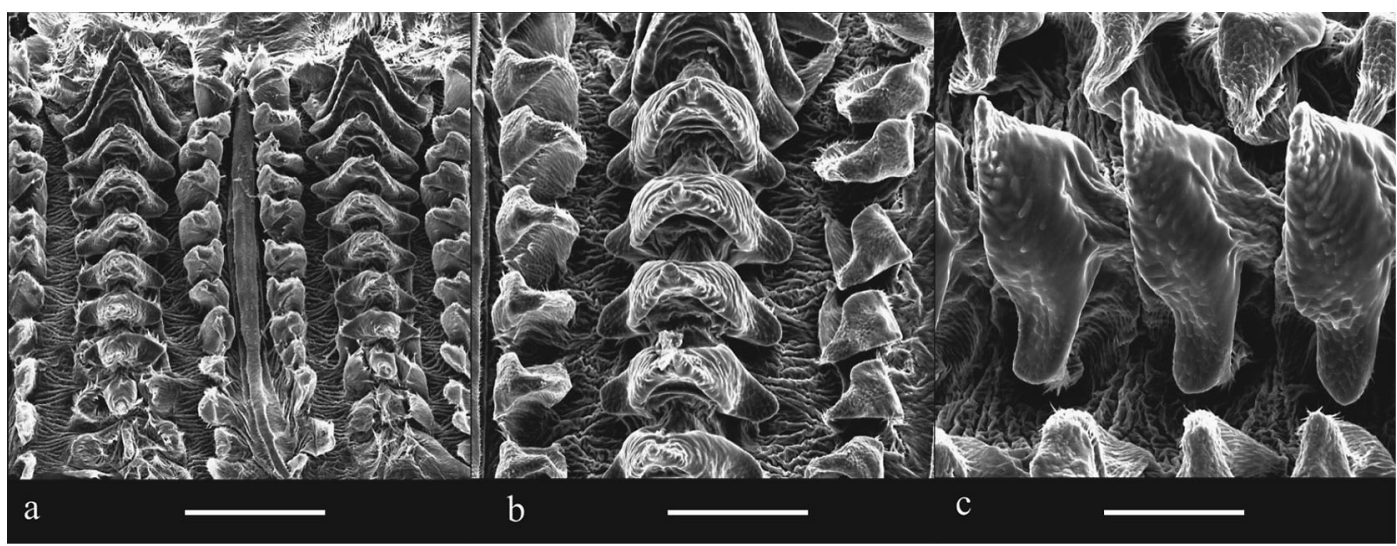

Fig. 5. Internal view of the proventriculus of Uvarovites inflatus (Uvarov 1924). - a. Distant view of longitudinal folds, scale $380 \mu \mathrm{m}$. - b. One longitudinal fold, scale $200 \mu \mathrm{m}$. - c. Lateral view of sclerotized appendices, scale $120 \mu \mathrm{m}$. 


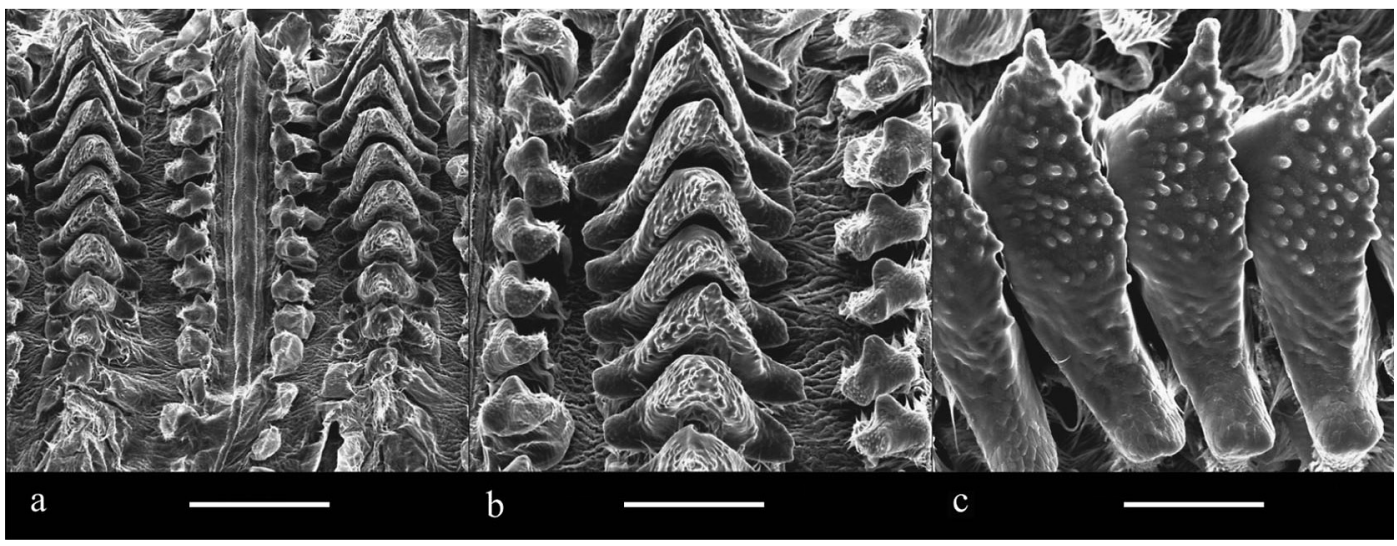

Fig. 6. Internal view of the proventriculus of Metrioptera ussuriana (Uvarov 1926). - a. Distant view of longitudinal folds, scale $380 \mu \mathrm{m}$. - b. One longitudinal fold, scale $200 \mu \mathrm{m}$. - c. Lateral view of sclerotized appendices, scale $100 \mu \mathrm{m}$

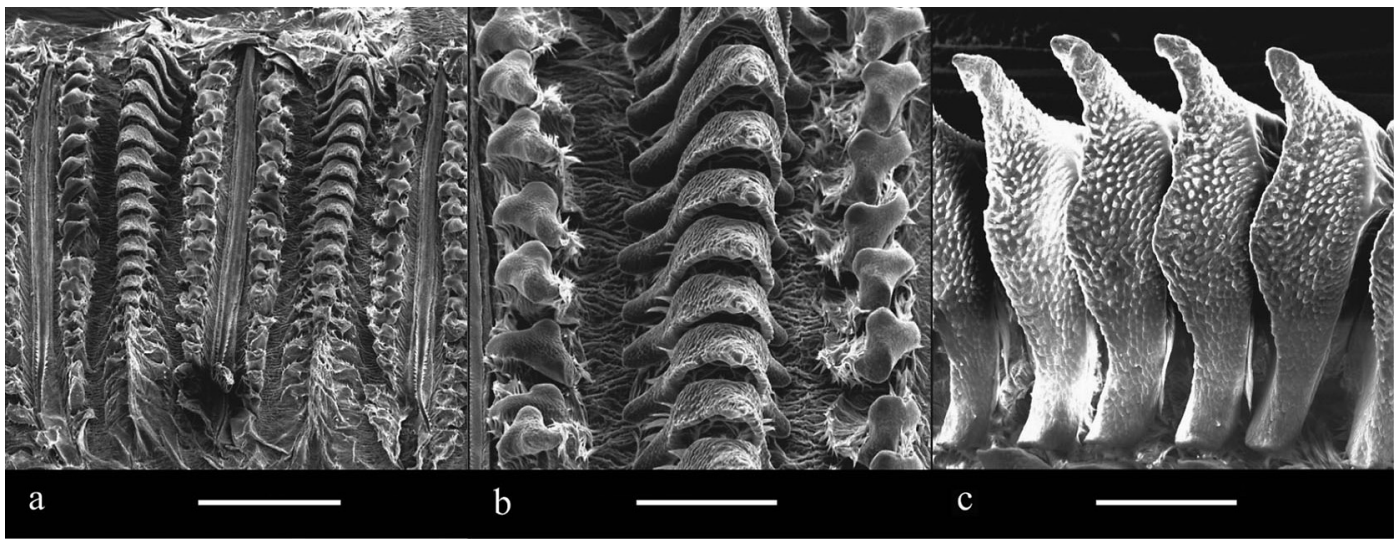

Fig. 7. Internal view of the proventriculus of Atlanticus sinensis (Uvarov 1923). - a. Distant view of longitudinal folds, scale $750 \mu \mathrm{m}$. - b. One longitudinal fold, scale $270 \mu \mathrm{m}$. - c. Lateral view of sclerotized appendices, scale $176 \mu \mathrm{m}$.

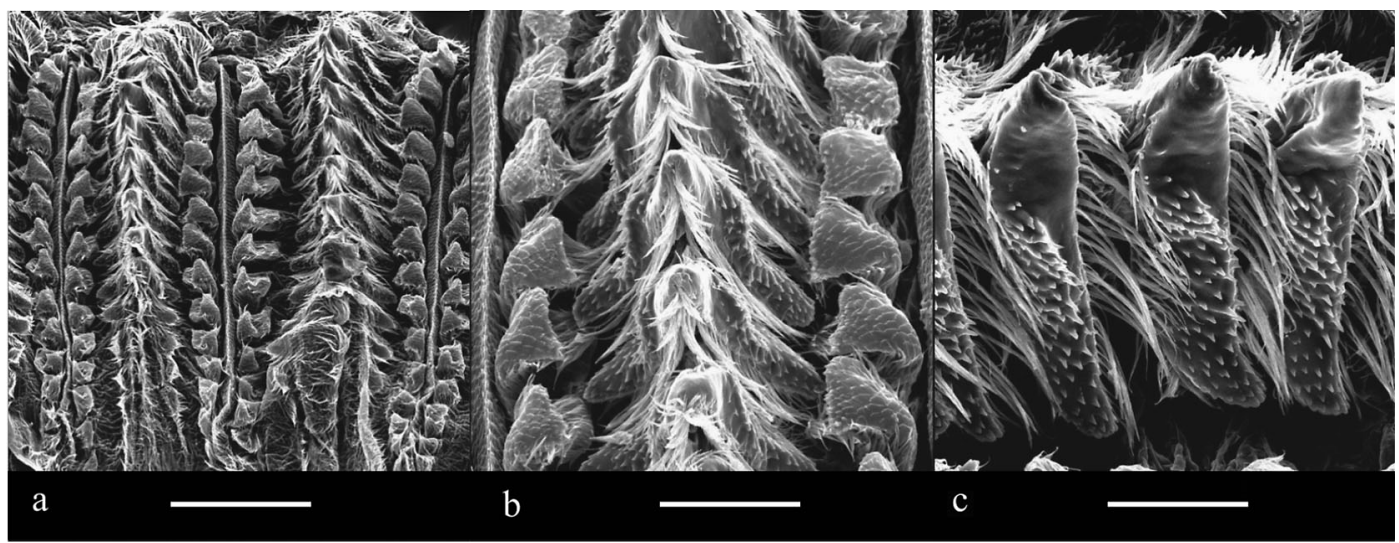

Fig. 8. Internal view of the proventriculus of Ducetia japonica (Thunberg 1815). - a. Distant view of longitudinal folds, scale $270 \mu \mathrm{m}$. - b. One longitudinal fold, scale $100 \mu \mathrm{m}$. - c. Lateral view of sclerotized appendices, scale $75 \mu \mathrm{m}$. 


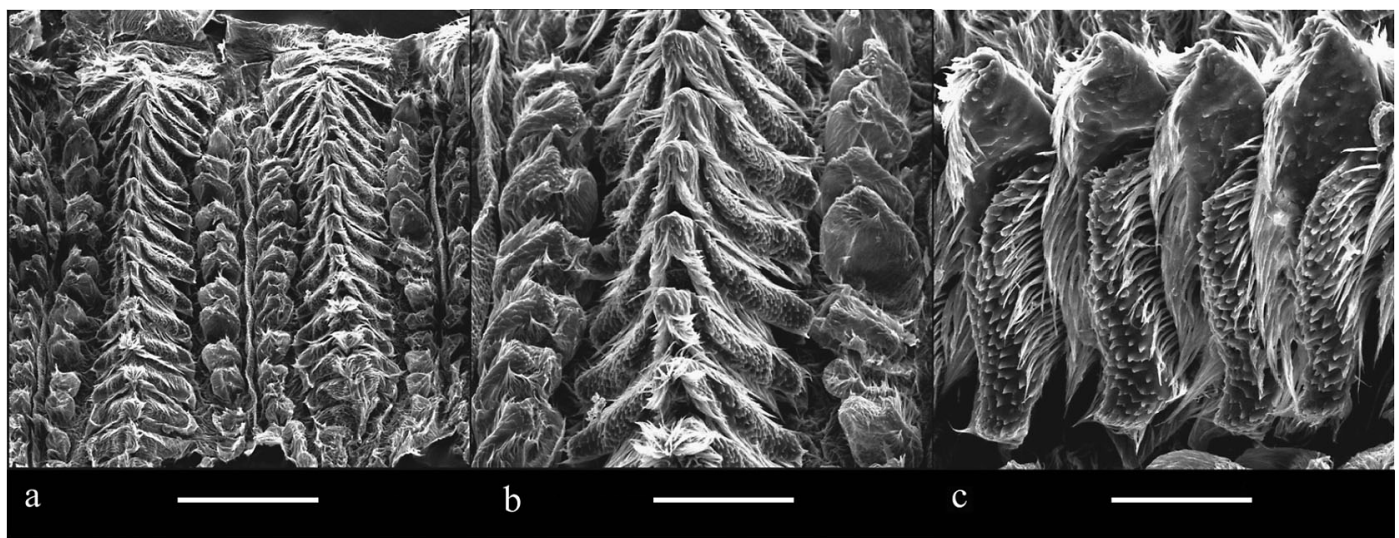

Fig. 9. Internal view of the proventriculus of Elimaea fallax (Bey-Bienko 1951). - a. Distant view of longitudinal folds, scale $380 \mu \mathrm{m}$. - b. One longitudinal fold, scale $150 \mu \mathrm{m}$. - c. Lateral view of sclerotized appendices, scale $86 \mu \mathrm{m}$.

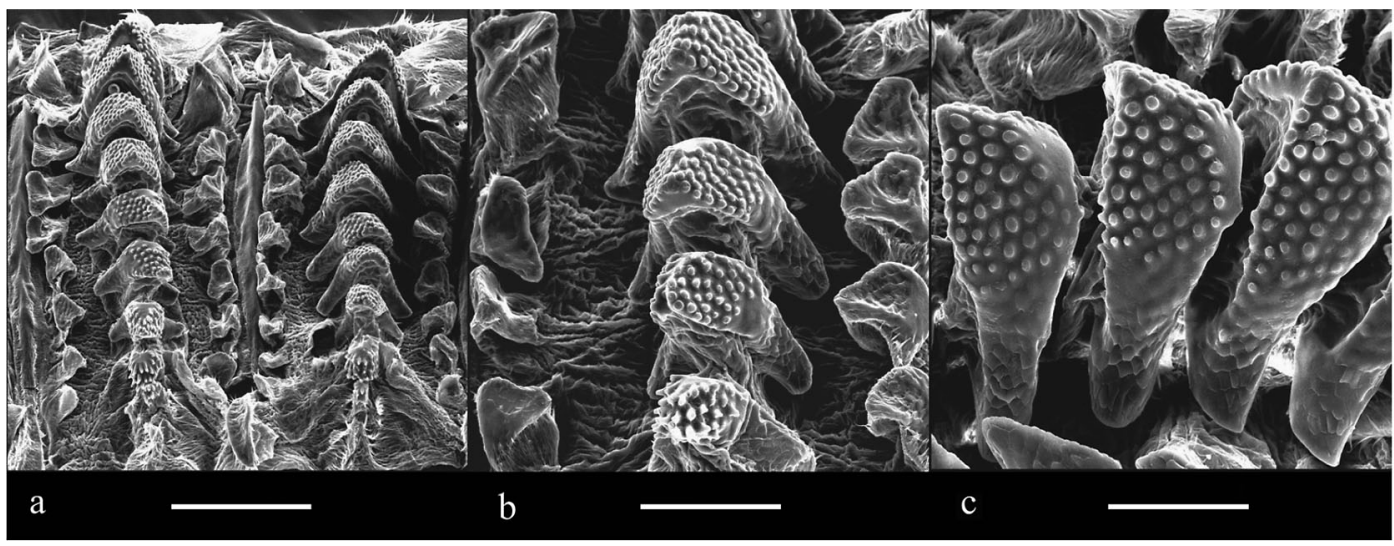

Fig. 10. Internal view of the proventriculus of Conocephalus fuscus (Fabricius). - a. Distant view of longitudinal folds, scale $231 \mu \mathrm{m}$. - b. One longitudinal fold, scale $100 \mu \mathrm{m}$. - c. Lateral view of sclerotized appendices, scale $75 \mu \mathrm{m}$.

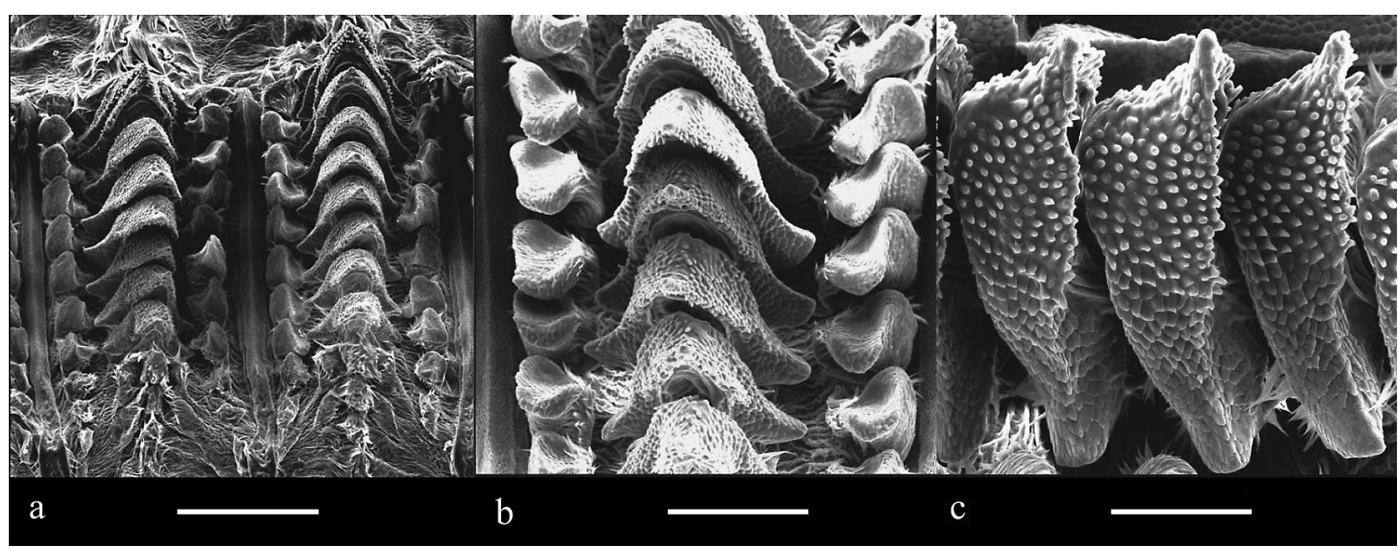

Fig. 11. Internal view of the proventriculus of Ruspolia jezoensis (Matsumura \& Shiraki 1908). - a. Distant view of longitudinal folds, scale $380 \mu \mathrm{m}$. - b. One longitudinal fold, scale $176 \mu \mathrm{m}$. - c. Lateral view of sclerotized appendices, scale $100 \mu \mathrm{m}$. 


\subsection{Structure of proventriculus}

Five characters of proventriculus were analyzed among all the species, which were the length of proventriculus, the number of $s a$ on each longitudinal fold, the length and width of $s a$, and the width of $s p$ between adjacent rows (Table 3 ).

The proventriculus of all the species examined showed the basic morphological pattern for katydids, i.e. it was formed by six longitudinal folds with complex rows of heavily sclerotized teeth. The sclerotized appendix $(s a)$ was formed of a central projection, the medium tooth $(m t)$ and two lateral expansions, the lateral teeth $(l t) . S a$ was covered with some mastoids (Fig. 2c), scales (Fig. 3c) and cilia (Fig. 4c). These varied with species. On either side of the rows of $s a$, small expansions could be observed, called sclerotized lobes $(s l)$ (Figs. 2, 3, 5). Bundles and rows of bristles lined the bases of the teeth. There was a sclerotized partition $(s p)$ between adjacent rows (Fig. 2).

\subsubsection{Tettigoniinae}

The studied species of Tettigoniinae had $s a$ covered with some scales and cilia on the base of it. They also had an obvious $m t$. The structures of the proventriculus also varied among the different genuses. Species of Gampsocleis had a relatively smooth $s a$ covered with irregular mastoids, with cilia on the base. This genus had the longest proventriculus of all the species we studied, because these species also had a larger body than the others (Table 2). In species of Uvarovites, $m t$ was not very obvious compared with the other species, and the top of $m t$ bended toward the body, with thinning cilia on the base (Fig. 5). Species of Tettigonia had a similar proventriculus to that of the genus Gampsocleis, but they were smaller and the mastoids distributed on $s a$ were more regular than in Gampsocleis (Fig. 3). In species of Metrioptera, the mastoids were mainly distributed on the top of $m t$, and there were thick cilia on the base of $l t$ (Fig. 6). In species of Atlanticus, a slender and sharp $m t$ could be observed on $s a$, and there were also thick cilia on the base of $l t$ (Fig. 7).

\subsubsection{Phaneropterinae}

The proventriculus of this subfamily was generally smaller than that of the subfamily Tettigoniinae. They had a smooth $m t$ and always extremely thick and long cilia distributed all over $s a$. There were no considerable differences in the specific structure of the proventriculus among the three genuses Phanerotera, Ducetia and Elimaea (Figs. 4, 8-9).

\subsubsection{Conocephalinae}

The species of Conocephalinae had no cilia on the $s a$, and $m t$ was not obvious. The top of $s a$ was covered with mastoids and scales distributed on the base. There was no considerable difference between the two genuses, Conocephalus and Ruspolia (Figs. 10, 11).

\section{Discussion}

Despite their same basic anatomical features, the inner structures of proventriculus showed diversity among three subfamilies of Tettigoniidae. The features of proventriculus and the length of each part of the alimentary canal were highly associated with the feeding habits. As early as in 1966, Uvarov discussed the relationship between the shape of the digestive system and feeding habits of Orthoptera species (Uvarov 1966). But feeding habits of most katydids were still unknown. Berneys and Chapman (1970) identified the feeding habits of Orthoptera species by the undigested food in the guts.

Our results showed that the species of the subfamily Phaneropterinae have a short foregut and a longer midgut and hindgut, may be because these species are carnivorous or omnivorous insects, and their food items are easier to be grinded than those of herbivorous species. The foregut is the main place for grinding food, so herbivorous species need a larger one. Species of the subfamily Conocephalinae, mostly herbivorous insects, have a longer foregut but a short midgut and hindgut.

The inner structures of proventriculus were also highly associated with the feeding habits. In the subfamily Phaneropterinae, the mastoids on 
the $m t$ were not obvious and there always were long cilia on the base of $s a$. The function of these long cilia might be to help them to transport the semi-liquid food. In the subfamily Conocephalinae, the tooth of proventriculus was highly sclerotized, and had many mastoids covered with $m t$. We assume that the function of these mastoids is to grind the vegetable food, such as plant fibers and pieces of leaves. In the subfamily Tettigoniinae, the species of which are mainly omnivorous, the characters of the proventriculus are also intermediate between the subfamilies Phaneropterinae and Conocephalinae.

There are more than 6,000 described Tettigoniidea species which belong to 1,199 genuses around the world (Eades et al. 2012). Our results cover only a little fraction of the whole family. However, our study includes most of the common species which occur in China, and gives a better understanding of the alimentary canal of katydids. Furthermore, we examined the anatomical aspects of the alimentary canal and proventriculus of Tettigoniidae for the first time and discussed their relationship to their diet. Further examination of more Tettigoniidae species are needed for a robust assessment of Tettigoniidae phylogeny and feeding habits.

Acknowledgements. This work was supported by the Natural Science Foundation of China (No. 31172133) and the Fundamental Research Funds for the Central Universities (No. 11SSXT153). We are extremely grateful to Carlos Pena and an anonymous referee for the valuable comments on the manuscript. Thanks also to the members of our lab for collecting material. This study was supported by the Central Lab, School of Life Sciences, Northeast Normal University, Changchun, China.

\section{References}

Bland, R. G. \& Rentz, D. C. F. 1991: Studies in Australian gryllacrididae: The proventriculus as a taxonomic character. - Invertebrate Taxonomy 5: 443-455.

Caetano, F. H. 1988: Anatomia, histologia e histoqu1'micado sistema digestivo e excretor de opera' rias deformigas (Hymenoptera, Formicidae). — Naturalia 13:129-174. [In Portuguese]
Chapman, R. F. 1998: The Insects Structure and Function. - Cambridge University Press, Cambridge, pp. 3840.

Eades, D. C., Otte, D., Cigliano M. M. \& Braun H. 2012: Orthoptera Species File Online. Version 2.0/4.0. http://Orthoptera.SpeciesFile.org (Site visited on 10 March, 2012).

Fontanetti, C. S. \& Zefa, E. 2000: Morphological characterization of the proventriculus of Gryllus assimilis Fabricius (Orthoptera, Gryllidae). — Revista Brasileira de Zoologia 17: 193-198.

Fontanetti, C. S., Zefa, E., Passetti, F., Mesa, A. 2002: Morphological characterization and comparative analysis of the proventriculus from three species of Endecous Saussure, 1878 (Orthoptera: Gryllidae: Phalangopsinae). — Entomotropica 17: 15-23.

Gibbs, D. G. 1967: The proventriculus of some trichopterous larvae. - Journal of Zoology 152: 245-256.

Isely, F. B. \& Alexander, G. 1949: Analysis of insect food habits by crop examination. - Science 109(2823): 115-116.

Judd, W. W. 1947: The proventriculus of Macrobasis unicoior Kirby (Coleoptera: Meloidae). - Annals Entomological Society of America 40: 518-521.

Judd, W. W. 1948: A comparative study of the proventriculus of Orthopteroid insects with reference to its use in taxonomy. - Canadian Journal of Research 26: 93161.

Lebrun, D. 1985: Structure digestives et regimes alimentaires des termites. - Actes Collection Insectes Sociaux 2: 43-44.

Li, N. \& Ren, B. Z. 2007: Karyotypes of Tettigoniidae (Orthoptera: Tettigonioidea) in Northeast China. Zootaxa 1457: 61-68.

Roche, R. K. \& Wheeler, D. E. 1997: Morphological specializations of the digestive tract of Zacryptocerus rohweri (Hymenoptera: Formicidae). - Journal of Morphology 234: 253-262.

Serrão, J. E. 2001: A comparative study of the proventricular structure in corbiculate apinae (Hymenoptera: Apidae). - Micron 32: 379-385.

Serrão, J. E. 2005: Proventricular structure in solitary bees (Hymenoptera: Apoidea). — Organisms, Diversity \& Evolution 5: 125-133.

Serrão, J. E. 2007: Proventricular structure in the bee tribe Augochlorini (Hymenoptera: Halictidae). - Organisms, Diversity \& Evolution 7: 175-180.

Uvarov, B. P. 1966: Grasshoppers and locusts: a handbook of general acridology. - Cambridge University Press, Cambridge, Vol. I.

Yahiro, K. 1990: A comparative morphology of the alimentary canal in the adults of ground-beetles (Coleoptera). - Esakia 1: 35-44. 